\title{
The next step in transcatheter aortic valve implantation: Transcatheter aortic valve replacement (TAVR) with BASILICA in a patient with a degenerated self-expanding transcatheter heart valve
}

\author{
Krzysztof Ściborski', Artur Telichowski', Marek Mak², Agnieszka Wysokińska-Kordybach', Filip Klausa², \\ Grzegorz Cieliński ${ }^{3}$, Dorota Kustrzycka-Kratochwil ${ }^{1}$, Waldemar Banasiak ${ }^{1}$
}

'Department of Cardiology, $4^{\text {th }}$ Military Hospital, Wroctaw, Poland

2Department of Cardiac Surgery, $4^{\text {th }}$ Military Hospital, Wrockaw, Poland

${ }^{3}$ Department of Anesthesiology and Intensive Therapy, $4^{\text {th }}$ Military Hospital, Wrockaw, Poland

\section{Correspondence to: Krzysztof Ściborski, MD, PhD, Department of Cardiology, $4^{\text {th }}$ Military Hospital, Weigla 5, 50-981 Wrocław, Poland, \\ phone: + 48261660452 , e-mail: k.sciborski@op.pl Copyright by the Author(s), 2022 DOI: 10.33963/KP.a2021.0193 \\ Received: \\ October 26, 2021 \\ Accepted: \\ December 29, 2021 \\ Early publication date: December 30, 2021}

The risk of coronary artery obstruction following transcatheter aortic valve replacement (TAVR) is 4-fold higher for valve-in-valve procedures (i.e., in the presence of a previous bioprosthesis) [1]. However, the highest risk may be associated with TAVR procedures in patients with failing transcatheter heart valves (TAVR-in-TAVR) because of reduced neosinus, tall valve leaflets, and, in some cases, additional supra-annular valve design. Bioprosthetic aortic scallop intentional laceration to prevent iatrogenic coronary artery obstruction (BASILICA) is a novel procedure for preventing coronary artery obstruction during TAVR [2]. It involves splitting the leaflet in two so that it cannot block the coronary artery once it has been pushed aside by the new transcatheter heart valve. Since 2018, several hundred BASILICA procedures have been performed worldwide, including in Poland, in patients with native aortic valve or surgical bioprosthesis $[2,3]$. However, so far, only a few cases of TAVR-in-TAVR with BASILICA have been described [4].

We report a case of a 63-year-old woman who underwent TAVR with a self-expanding $29 \mathrm{~mm}$ CoreValve (Medtronic, Dublin, Ireland) and developed structural valve deterioration with predominant stenosis 7 years later (max/mean gradient, 83/50 mm Hg; aortic valve area, $0.9 \mathrm{~cm}^{2}$ ). Because of high surgical risk, redo TAVR was planned. Computed tomography revealed a takeoff of the left main artery $1 \mathrm{~mm}$ above the level of the CoreValve cusps (Figure 1A-B).

Considering the high risk of the left main coronary artery obstruction with degenerated CoreValve leaflet, we decided to perform TAVR-in-TAVR with BASILICA. For femoral access, 18-Fr and 7-Fr sheaths were used. A multipurpose catheter was advanced via the 7-Fr introducer to deliver a vascular snare into the left ventricular outflow tract. Under transesophageal echocardiography guidance, an Amplatz Left 2.0 catheter was advanced via the 18-Fr sheath and placed above the degenerated valve, near the left main coronary ostium. A Piggyback Wire Converter (Teleflex, Wane, PN, US) microcatheter with an electrified $300 \mathrm{~cm}$ Astato $X 20$ guidewire (Asahi Intecc Co., Seto, Japan) was advanced to puncture the leaflet at $40 \mathrm{~W}$ (Figure 1D). Next, the wire was snared into the multipurpose catheter (Figure 1E). The microcatheter was pulled out to create a $V$ shape on the guidewire and scrape off the outer layer to form an "electric knife". The knife was advanced to the leaflet by pulling the snare and pushing the microcatheter, and it was then used to split the leaflet in two while simultaneously pulling both catheters at $70 \mathrm{~W}$ (Figure 1F). Before the procedure, a pigtail catheter with a stiff guidewire was advanced via the $18-\mathrm{Fr}$ sheath into the left ventricle in case of hemodynamic instability requiring urgent valve implantation. After BASILICA, we noted signif- 

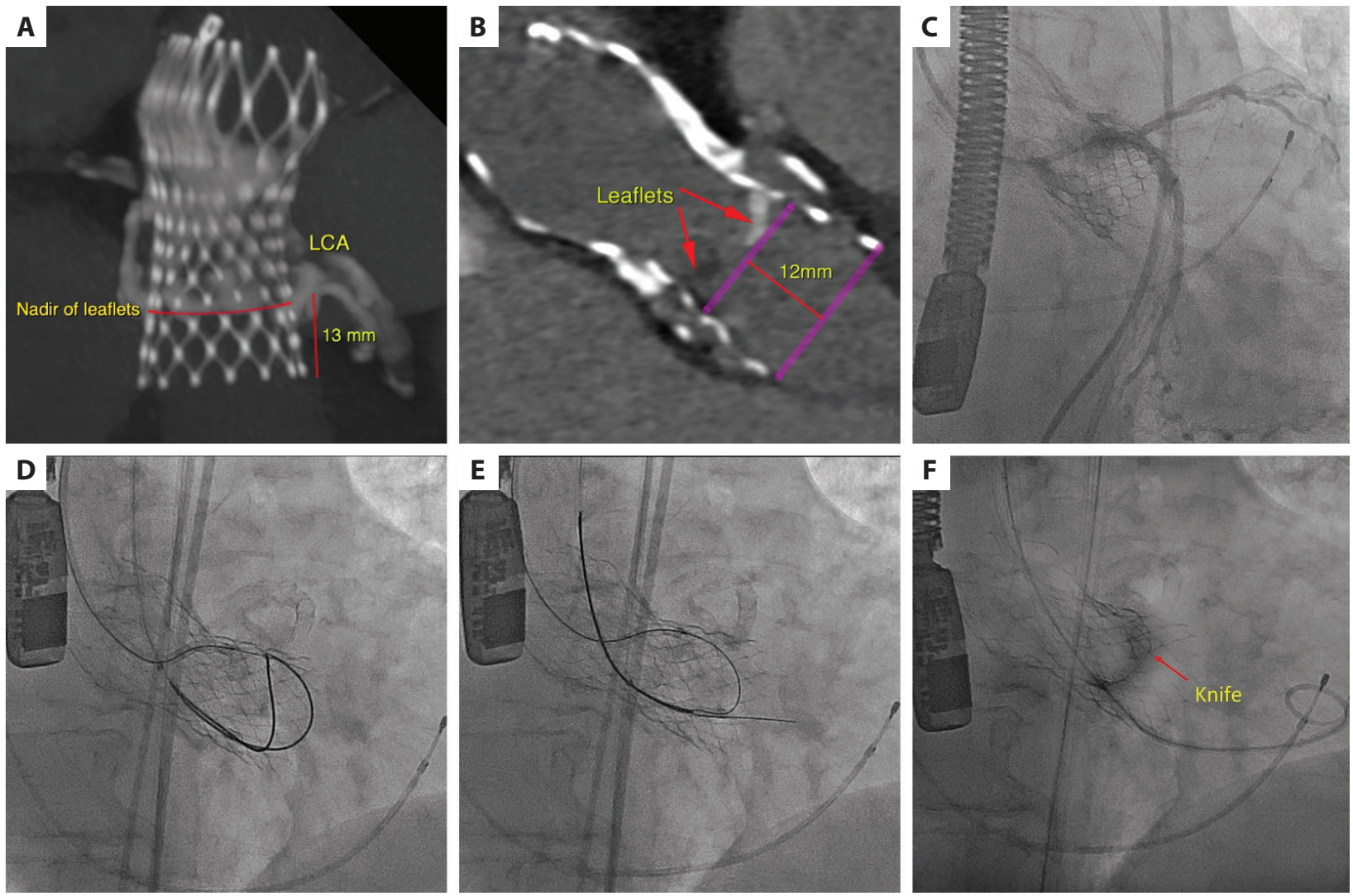

Figure 1. A-B. The coronary artery and CoreValve cusps on computed tomography. C. Coronary artery flow after the transcatheter aortic valve replacement (TAVR-in-TAVR). D. BASILICA technique: puncture of the leaflet. E. BASILICA technique: wire snaring. F. BASILICA technique: laceration of the leaflet

Abbreviations: TAVR, transcatheter aortic valve replacement

icant aortic valve regurgitation but without hemodynamic compromise. An Edwards Sapien 3 valve was implanted (Edwards Lifesciences, Irvine, CA, USA). Coronary artery flow was normal, and the procedure was successful (Figure 1C).

The use of BASILICA in TAVR-in-TAVR remains controversial [5]. However, as the number of patients with degenerated aortic valves after TAVR will continue to rise, large-volume centers have to become familiar with this technique in order to reduce the risk of fatal complications in this population, such as coronary artery obstruction.

\section{Article information}

Conflict of interest: None declared.

Open access: This article is available in open access under Creative Common Attribution-Non-Commercial-No Derivatives 4.0 International (CC BY-NC-ND 4.0) license, allowing to download articles and share them with others as long as they credit the authors and the publisher, but without permission to change them in any way or use them commercially. For commercial use, please contact the journal office at kardiologiapolska@ptkardio.pl.

\section{REFERENCES}

1. Ribeiro HB, Webb JG, Makkar RR, et al. Predictive factors, management, and clinical outcomes of coronary obstruction following transcatheter aortic valve implantation: insights from a large multicenter registry. J Am Coll Cardiol. 2013; 62(17): 1552-1562, doi: 10.1016/j.jacc.2013.07.040, indexed in Pubmed: 23954337.

2. Khan JM, Dvir D, Greenbaum AB, et al. Transcatheter laceration of aortic leaflets to prevent coronary obstruction during transcatheter aortic valve replacement: concept to first-in-human. JACC Cardiovasc Interv. 2018; 11(7): 677-689, doi: 10.1016/j.jcin.2018.01.247, indexed in Pubmed: 29622147.

3. Protasiewicz M, Kosowski M, Onisk G, et al. Bioprosthetic aortic scallop intentional laceration to prevent iatrogenic coronary artery obstruction (BASILICA): the first experience in Poland. Kardiol Pol. 2021; 79(10): 1149-1150, doi: 10.33963/KP.a2021.0069, indexed in Pubmed: 34292560.

4. Abdel-Wahab M, Kitamura M, Krieghoff C, et al. BASILICA for a degenerated self-expanding transcatheter heart valve: structural considerations for supra-annular prosthetic leaflets. JACC Cardiovasc Interv. 2020; 13(6): 778-781, doi: 10.1016/j.jcin.2019.10.008, indexed in Pubmed: 32113930.

5. Khan JM, Bruce CG, Babaliaros VC, et al. TAVR roulette: caution regarding BASILICA laceration for TAVR-in-TAVR. JACC Cardiovasc Interv. 2020; 13(6): 787-789, doi: 10.1016/j.jcin.2019.10.010, indexed in Pubmed: 32192701. 